\section{THE PROFESSION IN LEEDS.}

\section{To the Editor of ThE LANCET.}

Sir,-Allow me to call your attention, and that of your readers, to the lowness of the medical fees in Leeds and its neighbourhood. As a rule, if a medical man wishes to get on here, he must conform to the general rule, and charge the magnificent sum of eighteenpence for a visit upon a working man, who lives in a ten or twelve pound house, and pays rates. This fee also is the same even if medicine is sent out. Again, to a person who lives in a forty or fifty pound house, half-a-crown for a visit and medicine is considered quite sufficient. A shopkeeper, with a good business, will, in some parts of the town, haggle with a professional gentleman till he gains his end by obtaining a reduction of, say, a two pound bill to twenty-five or thirty shillings. A medical man begins practice, and in order to get patients he charges very low. He gets on, and still sticks to the same fees in most cases; the consequence is that the patients are ruined, and it is difficult for another medical man, who wishes to uphold his profession, to get on. A person employs him, he does his duty and attends well to his patient, sends his account in, and is told that Dr. So-and-so did not charge more than eighteenpence for visit and medicine. This is no solitary case, for the system of underselling is carried on in nearly every quarter of the town. The profession is split by petty jealousies, instead of being united for their mutual protection. Of course there are many honourable exceptions. Clubs are taken at half-a-crown per member per annum; and I can assure the readers of your valuable paper that a club appointment is striven for most vigorously. The clubs in Leeds are our masters at present; how long we shall be in subjection to them depends upon the efforts of medical men themselves to reform these abuses. Whilst I am on this subject, I may as well state that the fees for midwifery are fifteen shillings, if paid in the month, afterwards a guinea. This is very good if we could only be paid, but many a fee we lose for want of a better regulation. The only plan to obtain our fee in these cases is to let it be an understood thing that as soon as a labour is over the fee is to be paid down. It is as easy to pay it at once in such a case as within a month. I trust these remarks may be followed by a new era for good in Leeds. Let the medical men of this town, and throughout England, combine to raise our profession, and to exemplify the motto "Union is strength." - I am, Sir, yours faithfully,

H. ARthur Allibutit, L.R.C.P. \& S.

Russell Lodge, Sheepscar-street, Leeds, Dec. 21st, 1870.

\section{NAVAL PROMOTIONS.} To the Editor of THE LANCET.

Srr,-There is a letter in your issue of to-day, signed "Causticus," which I think all honest men will regret to see, and which requires an answer on public grounds.

I pass over "Causticus's" scandalous invocation of the Contagious Diseases Act, under cover of which he attacks the two late promotions to the rank of Deputy InspectorGeneral of the Navy, as if they were "quod hoc propter hoc," by saying that in the one case the rank is merely honorary, and to be held only during the time the position of inspector of hospitals under the Act in question is held; while in the other the appointment held under the Act was accepted only on condition that it did not interfere with his advancement in the service; and that in both cases these officers endeavoured zealously and laboriously to carry out the provisions of an Act passed by the Legislature, and approved by the profession; and that, instead of being a reward for their services in this respect, promotion was but a fitting climax to like zealons and skilful professional duty, performed in both cases for a period considerably ôver a quarter of a century in all quarters of the globe.

- Under a jumble of spite, Mars, Venus, Juno, and stale Latin quotations, I can gather that "Causticus" objects to these promotions because neither of the recipients had been engaged before the enemy, or held an appointment as staffsurgeon in a hospital. I answer that these cannot fall to the lot of every man in the service, and that it would be a gross injustice to pass over men of bigh standing, professionally and otherwise, who have done their duty with skill and zeal in other spheres, simply because some other man, perhaps much junior, had been engaged in some obscure warfare, or held an appointment indiflerently well in a naval hospital. Has there been no practice in the Navy on which to found a reputation, except in our hospitals, or in some skirmish in China, or a fer cases seen during a winter in the Crimea? Any fool may have been fated to see service before an enemy. It will not, therefore, qualify him for the highest honours of the profession. Men of very ordinary ability have held appointments in hospitals, and failed most signally in showing that they merited further advancement.

On the whole, I repeat that it is to professional ability alone that you are to look in the men who are to hold the most responsible positions in the Nary; and I feel certain that, viewed in this light, the promotions in question will be received with perfect approval by the service generally.

I trust to your sense of justice to give insertion to this letter.-I am, Sir, sour obedient servant,

December 31 st, 1870.

A Staff Surgeon, R.N.

\section{Goituman.}

\section{DR. W. CALLENDER TIDY.}

Dr. W. Callender Tidr, whose death took place on Christmas Day, at his residence, The Hollies, Mare-street, Cambridge-heath, Hackney, at the age of seventy-two, had been in general practice in the district upwards of forty years. The Doctor was a native of North Shields, where he received a good education in the classics and in mathematics. On leaving school, he was placed as a pupil to the late Mr. Trotter, a surgeon of great repute in North Shields, in whose surgery he continued for six years. Though the time may appear long for a medical apprenticeship, with Dr. Tidy it was not time wasted, as he embraced the opportunity for reading general literature and elementary scientific works, and in studying pharmacy; but especially it enabled him to become an adept in minor surgery. At the termination of his apprenticeship he came to London and entered as pupil at the Middlesex Hospital. In 1821 he became a member of the Society of Apothecaries, and in 1822 a member of the Royal College of Surgeons. On receiving his surgical diploma, he accepted an appointment as assistant to a surgeon in the country, which he held for a short time. He returned to London, and purchased a small practice at Cambridge-heath; and in 1834 he married. After his marriage he cultivated his practice with increased energy, and from that period he had no reason to dread the res angusta domi which so many practitioners have had to contend with; on the contrary, he was possessed of ample means, and surrounded by all the domestic comforts which make life enjoyable. It was not until 1852 that he graduated at King's College, Aberdeen. Dr. Tidy has left a widow, three sons, and one daughter. The eldest son holds an appointment in the civil service in India, the second is in the Church, and the third is attached to the London Hospital as lecturer on chemistry. The Doctor's death is a severe bereavement, which must be keenly felt alike by his family, his friends, and his patients. He lived the life of a good Christian, and died a true believer.

\section{THOMAS ROSS, M.R.C.S., L.S.A.}

IN the decease of this most estimable practitioner the West Riding has lost one of the old school who, modernised. in sentiment and culture, linked the present with a past generation. Mr. Ross was a student of the Borough Hospitals and of Grainger's School, and settled early in Wakefield, where he continued to practise till a few months ago.

Hospital Sundax at Liverpool.-The Mayor of Liverpool, at the Council meeting held this week, announced his intention of marking his approval of the Hospital Sunday movement by attending the parish church of St. Nicholas in his official capacity on Sunday next, which is the day selected for the simultaneous collections in all the churches and chapels of the town in aid of the public hospitals. 